\title{
Ecology in Context: A New Conceptual Frame
}

\author{
John Schooneveldt' \\ Fenner School of Environment and Society \\ Australian National University, Australia
}

\section{Abstract}

This paper reports on a developing theoretical frame for human ecology. It is based on the archetypal conceptual frames or contexts that underpin all scientific endeavors and draws on the new powerful techniques of semantic analysis. There are three archetypal scientific frames that have emerged since the Enlightenment, referred to here as the mechanistic, systemic, and interactive frames respectively. These three frames are conceptually distinct and each involves different levels of analysis. Each also operates with its own fundamental units: things (substantives or nouns) in the case of the mechanistic frame, processes (actions through time or verbs) in the case of the systemic frame, and events (experienced qualitatively) in the case of the interactive frame. All three frames are equally important for developing scientific understanding, but they are often confused in the scientific literature. Semantic analysis enables human ecologists to unscramble such confusion by drawing on the concept of archetypal meaning (sometimes referred to as the core or invariant meaning) and by defining and elaborating variations in meaning rigorously through the use of a natural semantic metalanguage (NSM). In addition, semantic analysis enables researchers to analyze the way motile organisms internalize their experiences by mapping the conceptual frame that they have internalized and use to make sense of those experiences. Traditionally, ecology and especially human ecology has been concerned with the interactions of organisms with each other and with their environment or context. It is argued that the interactive frame offers better explanations for evolution, creativity, and the experience of properties than the other two frames and provides a powerful explanatory frame for human ecology.

Keywords: agency, context, ecological interaction, interactivity, mechanism, quality, semantic analysis, system

1 Corresponding author: jcschooneveldt@iinet.net.au. 


\section{Introduction}

Ecology has long been thought of as the science of interactions between organisms and their environment. But what exactly is an interaction? Is it an entity or a process? This paper argues that an interaction is neither thing-like nor process-like: rather, an interaction is an event. Examples of events include claps of thunder, a river bursting its banks, and the conception, birth, or death of a living organism. A human decision is an event that takes place in the mind. Decisions are fully embodied events, both emotionally and cognitively. More generally, events involve numerous processes interacting together that can be thought of abstractly as a point in time where interacting things and processes create new contexts. The claim here is that an event orientation for ecology, and especially for human ecology, provides a unique frame for dealing with discontinuous change. It is argued that events resulting from an interaction create change. Neither organisms nor processes are creative in themselves. In other words, through the process of interacting with its environment, an organism triggers events of different sorts, some intended and some unintended. These events create new contexts. All organism-environment interactions are context-creating in this way and cannot be explained in terms of mechanism or process as traditionally understood.

In addition to dealing with interactivity, it will be argued that an event orientation provides a gateway for dealing with the human experience of quality including features, properties, characteristics, and evaluative experiences of all sorts. These include the experiences of color, dimension, shape, texture, and, of course, quality. If we think of physics and chemistry as the science of things (substantives or nouns), and thermodynamics and general systems theory as the science of processes (actions through time or verbs), then ecology is the science of properties (adjectives and adverbs in natural languages). Properties are the units of experience not only for humans but for all motile organisms. Even motile bacteria move toward things they find good and away from things they find bad on the basis of their subjective judgment. Judgments, like decisions, are events that involve interacting processes. They are neither mechanisms nor systems.

Properties have both a subjective and objective component: subjective when experienced directly as a participant within a contextual situation and objective when seen from the outside as an observer. A decision made by a motile organism is an event involving internal biochemical interactions. When acted out, that decision creates a new context. In the approach reported here, the evolution of language and the evolution of technology, like biological evolution, are the result of contextcreating events. As argued here, contexts are critical in making sense of creativity, emergent properties, and, as Darwin discovered a century and a half ago, evolution. 
Finally, it will be argued that an event orientation gives us a way into the subjective experience of organisms which is much richer than traditional push/pull, stimulus/ response, or action/reaction dynamics. It strongly suggests that organisms develop their action potential in terms of generalizations or rules in the form "if $\mathrm{X}$, then $\mathrm{Y}$," where $\mathrm{X}$ is an internalized contextual feature of a conceptual frame and $\mathrm{Y}$ a specific behavior.

\section{Why context?}

Whatever exists must exist somewhere, in some kind of place or context. As the philosopher Edward Casey (1997, p. ix) points out:

Place is as requisite as the air we breathe, the ground on which we stand, the bodies we have. We are surrounded by places. We walk over and through them. Nothing we do is unplaced.

This is a primal fact that calls out for recognition, not only in the case of physical places (such as the surface of a leaf, a pond, or a town) but also their metaphoric extension as conceptual (or internalized) contexts (such as a home territory or nation-state). Contexts are a property of mind. They do not exist independently of the experiencing organism. They have the very useful property of being able to be mapped on the basis of abstracted hypothetical meanings empirically ascribable to the individual or species of organism concerned. Traditional scientific measurement techniques are a special case of such mappings (discussed further below).

We humans recognize the importance of context when we are quoted out of context, when we misread a situation or observe others behaving inappropriately in one or another context. We spend a great deal of our waking lives observing, interpreting, and discussing contexts; whether we are dressed appropriately for the occasion, whether the organizational arrangements are suitable, and importantly, whether our reading of a situation is good enough to assess risks, identify options, and make sound decisions.

At the core of these internal deliberations (discussions when more than one individual is involved) is an exploration of whether our understanding of a situational context matches other understandings. Deliberative processes through dialog with others (or within ourselves) enable shared understandings to be developed - or at least an understanding of points of difference. Interpreting contexts correctly not only avoids what Goffman (1959) called situational improprieties; it generates good policies, produces innovative technologies, creates livable habitats, and aims at least to maintain and preferably improve the quality of life. 
Contextual thinking then is essential not only for interpreting the meaning or significance of foregrounded foci, it actually creates new contexts as they are acted out. Traditionally the humanities put a great deal of effort into describing relevant contextual factors, but they are largely assumed in the sciences. However, both fail to recognize that the act of setting down or documenting a context creates a new context. We already know this and experience it acutely when a child is born or a loved one dies - the world is no longer the same. But this is true for every action by every living organism. Their actions change contexts and thus are the creative events that really change the world. As we will see, context-changing events increase exponentially and offer a potential explanation for the increasing speed of biological, technical, linguistic, and, especially, cultural evolution.

At present, each academic discipline has its own conceptual frames, working methods, area of specialization, and widely accepted findings that are assumed valid, reliable, and useful for the discipline concerned. But these specializations result in an increasing fragmentation of knowledge. Context analysis offers a tool to translate across disciplines, and, where possible, to integrate findings. The development of the objective metalanguage needed for this task is a job for specialist linguists, just as the development of logic and mathematics (including statistics) are jobs for specialists. But the application of these powerful tools is a matter for all researchers.

First we need to recognize that contexts are important for all scientific disciplines. This is already recognized in evolutionary biology, which seeks to identify selection pressures as contextual features driving evolution and ecology. This includes describing ecological niches and biomes as the defining environmental features that each species of organism needs in order to live well. Some ecologists also illustrate the environmental features impacting on an organism diagrammatically as an envirogram (Andrewartha \& Birch, 1984), but these involve physical contexts only. Ecologists and evolutionary theorists lack the tools for analyzing conceptual (or subjective) contexts which motile organisms (including humans) draw on to make their judgments and decisions.

\section{Subjective and objective contexts}

Here it is claimed that there are two ways of thinking about contexts: objectively (seen from the outside) or subjectively (experienced from within). The outside view turns a context into an object, process, or event. From the inside, it is experienced as an affordance: a term invented by the psychologist James J. Gibson (1986). The outside view has describable properties that can be measured in some way (discussed further below). An objective context can even be thought of metaphorically, as though it is itself an agent. For example, we can think of the market as being jittery, a nationstate waging war, an idea going sour, and the gods being angry. The personification 
of contexts is metaphoric: markets, nation-states, ideas, and gods do not exist in fact, nor can they do anything. Rather, people do things in the context of markets and so on.

The core methods described here involve analyzing, testing and mapping internalized contexts objectively. Organisms do not interact with the world directly; they act out their internalized generalizations about their world and how they should act in it. These generalizations, as we will see, are internalized as rules and algorithms for living well and for avoiding the opposite.

Young children are brilliant at making sense of contexts. They learn the rules governing their native language and the social dynamics of their culture by interacting with it and internalizing its contextual features. Exactly how they do this remains deeply puzzling, but as child psychologist Vasudevi Reddy (2010) points out, it is not through some sort of conditioning processes, but rather children engage with the world from birth. They are active agents, experimenting, playing, and testing limits as they internalize the rules, roles, and the conceptual frames (or internalized contexts) that they need to interact with others and live their lives. Before they start kindergarten, children have learned their language, formed their personalities, and acquired the social skills that they will need to function successfully (or otherwise) for the rest of their lives.

As is well documented, when children play they set up imaginary contexts and make up the rules of the game as part of their socialization. Educators set up contextual situations in the classroom or in the field to adapt their material to the readiness of their students. Students are not empty vessels. Learning comes through the experience of interacting with and engaging with the contextual frame presented by the teacher. Environmental educators are particularly interested in making sense of contexts (Fisher \& Hoverman, 1989).

In addition to educators, creative artists set up contexts, for example, as a background to a painting or a theatrical stage, a movie set, or a descriptive passage in prose and poetry. Contexts can be physical, like road networks and urban infrastructure (bridges, buildings, water supplies, sewage treatment plants, and so on), or conceptual, like a set of religious beliefs, a legal or disciplinary framework, a scientific model, a theory, or even an idea.

It is important to stress that a context cannot be seen from the inside, it can only be experienced subjectively as an affordance. Gibson made up the term affordance to describe those features of the environment that are useful for an organism: a functional definition of what is experienced subjectively. For example, a bird might perceive a branch, not as a branch, but as functional action-oriented, sit-onable. A small moving animal might be thought of as chase-able to a dog. These are pragmatic functional realities: part of an organism's action potential. Seen this way, 
the world is experienced subjectively and is very different to the world described by physics and chemistry. The basic idea reported on here can be traced back to Jacob von Uexküll's (1957) idea of umwelt, which is sometimes translated as a perceptual world view (of an organism) or frame of mind, but such phrases are too broad for the specific contextual features that function as an affordance for an organism in any given situation.

It is important here not to confuse the subjective experience of an affordance with its mapping: an abstract conceptual frame that can be illustrated objectively as a diagram or a verbal description. This distinction is further elaborated below when the conventions of scientific measurement are discussed. First, a further psychological distinction needs to be drawn between the ways we experience the world intuitively and deliberatively.

\section{Thinking fast and slow}

The behavioral economist Daniel Kahneman (2011) distinguishes between fast thinking and slow thinking, a distinction that has been long recognized by psychologists in one form or another. Fast thinking, he argues, is subjective, intuitive, and based on the contextual frame what you see is all there is. He contrasts this with slow thinking, which is based on externalizing our experiences and objectifying them. The objective view enables us to analyze contexts in great detail, assess risks, develop options, design modifications, and act on them. Fast thinking can also lead to action, but such actions, according to Kahneman, are based on our animal instincts such as food preferences, fight/flight responses, and sexual attractiveness. They served our ancestors well long ago, he argues, but are less likely to do so in the context of our complex societal and institutional arrangements. The reference to animal instincts is far too vague for scientific purposes. Tools are emerging to enable us to map the frame what you see is all there is for specific organisms, as well as to analytically (and critically) examine the contextual frames that govern deliberative, slow, thinking.

In addition to the two ways of thinking, Kahneman and his colleagues have shown that there are two different selves within us: the experiencing self and the narrating self. The experiencing self involves our moment-to-moment conscious awareness that operates in the context what you see is all there is. It remembers nothing and is rarely consulted when making decisions. The narrating self is the brain's interpreter, spinning yarns about what is happening now and what happened in the past, as well as making plans for the future. Only the highlights are woven into the story that the self uses to orient the individual in the world and create the internalized contexts we draw on in making sense of our experiencing self.

There is nothing new here. Broadly speaking, the humanities have always sought to describe the subjective experience of contexts, while the sciences (both physical and social) have focused on making sense of their objective features. However, as 
the phenomenologists remind us, our subjective experiences are real, immediate, and constantly evolving. The objective view is artificially constructed through observation and experiment. While artificial, it is rigorous, and, like the built environment, has proven itself far more reliable and useful than the subjective. But this is only true if what economists call externalities are ignored. Highlighting unintended consequences of the application of discipline-based decision-making, exposing externalities and dealing with them are at the heart of human ecology.

In summary so far, humans (and all motile organisms) live in physical contexts and act out their internalized conceptualizations of these contexts. In the process, organisms create new contexts. The human species is superb at this, turning dangerous and threatening spaces into familiar and safe places, empty houses into homes, and a pile of clothes into a social statement about ourselves. Local communities and in-groups of various sorts form different types of context created by and existing primarily in the human mind. Lines on maps and fenced or walled borders are physical artifacts and secondary to the conceptual reality. Contexts are far more important than the activities that created them because the activities are short lived, but the contexts themselves are socially constructed and can survive for hundreds and sometimes thousands of years. For example, consider the persistence of territorial disputes, or religious beliefs and associated cultural practices. The contextual circumstances of organisms' experience drive evolution.

\section{Analyzing contexts}

As contexts are essential for making sense of what is under consideration in the foreground, a technique is needed for analyzing them. Here it is argued the emerging technique of semantic analysis is best suited for this purpose and offers a conceptual tool to add to our scientific tool box. Just as logic and mathematics are useful tools, semantic analysis offers a formal method for describing and defining meanings explicitly. It uses the techniques developed by cognitive scientists such as George Lakoff and Mark Johnson (Lakoff \& Johnson, 1980, 1999, on analyzing metaphor), Cliff Goddard (2011, on cultural scripts), and especially, Anna Wierzbicka (1985, 1988, 1996, 2003, 2014, on semantic primes and their application). While analyzing meaning is also of great interest to philosophers, they do it horizontally, by analyzing the meaning of words largely in terms of other words. Semantic analysis is an empirical science. Like linguistics and cognitive science, it analyzes meanings vertically by examining the interactions of real events, processes, and things with our conceptual or contextual understanding of them. It draws on the universal features of language as benchmarks and has both a subjective and an objective dimension.

To illustrate the technique, we next consider the three archetypal scientific frames that have emerged since the Enlightenment in some detail. These are the mechanistic, systemic, and interactive frames or contexts that scientific disciplines draw on in developing their theories and models about the world. 
To understand a context, we need to step outside it, as it were, and examine it objectively. This is difficult for people who have never experienced another culture, or who have been trained in a single discipline or raised in a single belief system. They lack a contextual frame outside their familiar one to step into. As Wierzbicka (2014) pointed out, they are trapped in their ethnocentric and narrow conceptual worldview. Fortunately, as more and more people are exposed to other cultures, different belief systems, or other disciplines, they are able to draw comparisons and escape their parochial cells.

One way to avoid entrapment in one's own mindset is to think about others not in relation to one's own contextual frame, but in relation to the archetypal thinking frames used by people for millennia: what Mary Midgley (2003) calls myths we live $b y$ or Carl Jung's primordial images and ideas he later called archetypes - core ideas that are universal to all humans. Archetypes can also be thought of as benchmarks or anchor points that have become empirically distilled over many generations through the medium of story-telling (Peterson, 1999). They are not simple metaphors but represent the fundamental empirical units of the human experience which, according to George Lakoff and Mark Johnson (1999), are embodied in the human psyche. They are the source of all metaphor. They also include the semantic primes that Wierzbicka and her colleagues have identified as universal to all human languages. The simplest way to think about semantic primes is to think of them as similar to the chemical elements that can be combined in various ways to create more complex molecules and substances of all sorts. In the same way, semantic primes can be combined to define meanings precisely using the natural semantic metalanguage (NSM) developed by these linguists. Again, this is not a new idea. It was first proposed by Leibniz over three centuries ago when he thought of it as an "alphabet of the mind" (Leibniz, [1704] 1903, p. 160-161; Wierzbicka, 1996, p. 13).

\section{The mechanistic frame}

This refers to the idea that the universe and everything in it operates mechanistically. People who hold this view are operating in a mechanistic frame or context. For them nothing is real until it can be explained in terms of specific push/pull, action/ reaction, or stimulus/response mechanisms. An extreme version of the mechanistic frame considers direct experience, especially the experience of free will, as delusional, and the experience of consciousness as the most difficult problem faced by science.

The mechanistic frame emerged during the Enlightenment period. It came at a time when Europeans were fascinated by automata of all sorts. Examples include mechanical clocks, mechanized scenes from history, and amusement pieces such as toy music boxes and fantastic garden displays of animals and mythological creatures in motion. The historian Jessica Riskin (2016) in The Restless Clock traced the history of the idea of mechanism as it came to inform philosophical and scientific thinking over the last 400 years. At the core of Riskin's history are two competing 
ideas of mechanism: the idea that mechanisms consist of mindless interacting parts (a view espoused by Descartes, Newton, and modern thinkers such as Dennett and Dawkins), and the idea that mechanisms are not made up of mindless bits and pieces but also involve some sort of agency or purpose (a view espoused by Leibniz, Lamarck, Whitehead, Charles Birch, and process philosophers generally). Darwin was puzzled not only between these two different mechanistic views, but puzzled over the very idea that life, and especially the experience of emotion and value, was mechanistic.

What is common to mainstream mechanistic thinkers, however, is the idea that the world and everything in it consists of things, items, objects, and entities that linguists describe as nouns in natural languages. Things in this view range in size from subatomic particles to galaxies. They include photons, atoms, complex molecules, living organisms (plants and animals), and large objects such as planets and stars. They also include conceptual things like minds, motives, and beliefs. The whole universe in this view is thing-like and everything is either a part of one thing or a collection of things.

In this dominant frame, things are in fully determined synchronic relationship with other things. They are either mindless entities governed by immutable physical laws in the Newtonian tradition or have some sort of emergent consciousness associated in the (minority) Whiteheadian and pan-psychic traditions, but they are things nevertheless.

\section{The systemic frame}

Some 200 years after the emergence of mechanistic thinking, a new archetypal frame emerged that can be described as the systemic frame. The fundamental units of this frame are not things but processes, actions, and behaviors that linguists describe as verbs in natural languages. In all languages, process words (verbs) carry tense markers. The idea that reality consists only of processes is also old, going back to the early Greeks in the West and the Buddhist tradition in the East, but it came into scientific orthodoxy through the work of the mathematician Jean Baptiste Fourier who studied the transfer of heat in solids. In 1811 he was awarded the prize of the French Academy of Science for showing that heat flow is proportional to the gradient of temperature (Prigogine \& Stengers, 1984, p. 104). This was the start of what is now known as thermodynamics. In this view, heat is not some sort of thing, but is a process involving energy transfer. Later this frame came to include the physical flows of liquids and gases and the feedback processes that regulate them. More recently the flow of information is being seen in systemic terms as part of general system theory. 
In the systemic frame, things are real enough, but they are temporary states in interacting processes. Their existence is temporary: they are always either coming into or going out of being through a specific set of processes including feedback processes. The process philosophy of Whitehead, Hartshorne, and Birch provides further elaborations of this tradition, as does the systems work of Jay Forester and many others.

Like the mechanistic frame, the archetypal systemic frame is fully deterministic, but causation does not involve simple push/pull interactions. Rather, causation is more nuanced as flows interact by merging, separating, and cycling as materials, energy, and information are transferred and transformed. Regulation is not through some sort of immutable physical laws, but through subtle feedback processes. While reversibility is theoretically possible in the mechanistic frame, it is not possible in the systemic frame. Time cannot flow backward.

The systemic frame does not replace the mechanistic frame but offers an alternative conceptual model based on the universal distinction between things (nouns) and processes (verbs). It provides a different level of analysis. One is not better or worse than the other. Both are necessary and both have considerable explanatory power: mechanisms best describe synchronic relationships between things while processes involve diachronic interactions and feedbacks. Some mechanistic thinkers have tried to explain change by positing a fourth dimension-time-which seems unnecessary and artificial as the systemic frame deals with time and change-overtime par excellence. A great deal of highly specialized work has been done to explain how biological phenomena might be explained in these two frames that will not be reviewed here. Rather, we leap over that history to report on a new frame that is claimed to better explain the evolution of living organisms.

\section{The interactive frame}

While the systemic frame is excellent for describing continuous change, it does not explain the stochastic, unpredictable, and increasingly complex changes associated with the evolution of life. The idea that species of organisms evolved can be traced back to the work of a number of French naturalists, especially Jean Baptiste Lamarck and his often maligned 1809 classic Philosophie Zoologique. But it came into scientific orthodoxy some 50 years later (at least among biologists) with the work of Alfred Russell Wallace and especially Charles Darwin. Nowadays Darwinian evolution is central to all biological understanding, not only among evolutionary biologists but also among geneticists, embryologists, physiologists, endocrinologists, virologists, botanists, ethologists, neuroscientists, and many other disciplines. 
The evidence for evolution is overwhelming and often regarded as the best supported of all scientific theories, but how exactly does it work? At its core is the idea that living organisms interact with each other and their environment. Those that do so successfully and reproduce pass on their successful characteristics to the next generation. Over long periods of time successful characteristics tend to survive and unsuccessful ones die out: what Darwin called natural selection. Since Darwin, some biologists have seen natural selection as a mechanism (e.g., de Beer, 1968) and others have seen it as a process. Here we reject both these ideas. Evolution is nondeterministic and unlike mechanisms and systems (as defined above). Individual organisms come into being as newly created forms that interact with their environment to create new contexts. The new contexts create new opportunities and pressures for other organisms to interact with. Evolution then is a sequence of context-creating events. It is not individual organisms, species, genes, or populations that evolve: it is the context that evolves. Living entities are part of a series of complex events going back to the beginning of life on Earth. Being alive is totally dependent on the life that has gone before and created the contextual conditions that enables the current generation of organisms to thrive. These organisms are mutually dependent on each other for food and the environmental conditions that enable the whole to thrive. Each is unique (even when closely related) as a result of a unique series of experiences or events. These events are discontinuous (stochastic) and largely unpredictable. In Dawkins' (1991) famous phrase, "evolution is blind," but unlike mechanisms and systems, evolution is also creative, and, as argued here, the context is what is created and selects.

This distinction is fundamental. If we take the archetypal mechanistic frame as involving fully determined bits and pieces in specific functional relationships with each other, creativity is impossible. Likewise, if we take the archetypal systemic frame as involving interacting processes that are also fully determined (in accordance with the laws of thermodynamics) creativity is also impossible. But an interactive approach that recognizes the role of context in the behavior of living organisms offers a frame for thinking about the creativity of life in general. The power of this interactivity cannot be doubted. The free oxygen in the atmosphere is created and maintained by living organisms; the oil, coal, and natural gas we now consume as energy sources were put there by living organisms, as are the limestone and cementiferous materials we use in construction. As Lovelock has pointed out as early as the 1960s, the whole biosphere is self-regulating through the interaction of living organisms. Finally, human activities are now so powerful that they are damaging the conditions under which humans themselves evolved and need for their continued survival. Even more significant is the speed at which contexts are changing. It took millions of years for living systems to deposit the fossil fuels and create the atmospheric conditions and biodiversity on which we depend. Humans are rapidly changing these conditions to a noticeable (and measurable) extent over mere decades. 
There is a huge and growing literature that attempts to build creativity into the basic systems frame, including, for example, adaptive systems, soft systems, evolving mechanisms, and emerging properties. Like positing a fourth (time) dimension to account for change in the mechanistic frame, such strategies seem somewhat artificial and arbitrary. Better to accept that mechanistic thinking cannot account elegantly for change and use the much more coherent and well-developed systemic frame for continuous action over time. So too, it is better to accept that systemic thinking cannot account elegantly for creativity involved in the way living organisms develop, adapt, and evolve. As will be argued below, these phenomena are contextdependent and do not readily fit the systemic frame. Rather, creativity can better be explained by recognizing a third archetypal frame, the interactive frame, to account for evolution.

Not only is evolution interactive, so are all biological processes including gene expression, neural transmission, learning, and all behavior. And not only organisms but all living cells interact with their environment, internalize their experiences, and act out their inner states in context, but not any context; only the context that is relevant and meaningful to them. This is not the context that is described by physics and chemistry (important though such explanations are for other purposes) - it is the context that living organisms internalize through experiencing the world in which they find themselves. It is through mapping these subjective internalized contexts that gives science a new methodology to advance our scientific understanding of the behavior of living organisms as they live out their lives. In the case of the human organism, it offers an explanatory frame for dealing with the way humans increasingly impact on the world in which they find themselves. The psychologist Jordan Peterson (1999) in his Maps of Meaning: The Architecture of Belief attempts to map archetypal meanings of human narratives in terms of Jungian archetypes. Peterson is not a linguist and does not have the sophisticated tools of semantic analysis available to him, but his technique is fully consistent with the approach adopted here.

Jonathan Kingdon (1993) referred to the human species as "Self-Made," and, more recently Yuval Noah Harari (2015) called the species "Homo Deus," but such phrases are misguided. It is the whole of life that is evolving. Humans are a part of this evolutionary dynamic — an increasingly important part, but not independent of it and certainly not in control of it. Simplistic mechanistic and systemic thinking has unintended consequences. It destroys much of the natural world that we value through the incorrect application of these frames. An interactive frame facilitates holistic thinking as humans plan for an unknown future and build resilience to deal with the unforeseen and unintended consequences of past actions. 


\section{Properties}

Properties are the units of experience. They describe an interaction between an individual and an aspect of context (including a thing, process, or event) that is in focus. They have both a subjective emotional or value-oriented dimension and a physical dimension at the same time. In natural languages, property words include words denoting features, characteristics, traits, aspects, and qualities. Such words are traditionally classed as qualifiers. Indo-European languages typically have several classes of qualifiers known as adjectives when they refer to things (nouns) and adverbs when they refer to processes (verbs). As pointed out by Dixon (1982), while most languages have rich and open classes of qualifiers, there are a few languages that do not have specific words that might be classed as adjectives or adverbs (notably Chinese), but all languages have specialized syntactic structures that are used to convey property-like meanings or qualities. Just as linguistic categories such as noun and verb are universal to all human languages, so too is the idea of qualifier. These linguistic categories are fundamental features of the experience of being human, like being bipedal and having large brains. They are also fundamental for scientific understanding.

In addition to making use of syntactic features to account for meaning, languages also make use of semantic roles to signify the relationship a word has with the main verb-for example, the roles of agent, beneficiary, causer, and experiencer. Languages are complex, involving not only physical entities such as words and other syntactic structures, but also subjective features such as semantic roles and property-like descriptors. Language itself is a bipolar phenomenon having both sense and reference.

Property-like concepts include references to color, size, texture, weight, number, gender, and evaluative concepts such as good/bad, many/few, true/false, and so on. They differ from nouns and verbs, which operate under the primary assumption of reference. As pointed out above, property-like concepts can be analyzed into two components: one referring to an object, process, or event, and the other referring to a speaker's subjective experience of it. The dual nature of sense and reference inherent in property words and other qualitative expressions has given philosophers much to argue about over the last 2,500 years, some claiming that properties are real and part of the world (philosophical realists) and others arguing that properties exist only in the mind (philosophical idealists). Here it is argued that they are both at the same time.

The human ability to switch contexts from subjective to objective and back gives us a new way of dealing with the conflicted views on properties. This involves a shift from a mechanistic (push/pull, action/reaction, stimulus/response) thinking style to the more complex idea of engagement where an organism is constantly interacting 
with its environment. Engagement in the case of humans involves interaction through all sense modalities at the same time. Rather than assuming that organisms are activated by drives, needs, and motives of various sorts, this perspective assumes organisms are basically active and not inert entities that need some sort of activating mechanism. There is a vast psychological literature dealing with needs, motives, and drives that seek to measure these hypothesized mechanisms and identify their underlying neural patterns, but such approaches become largely vacuous in an interactive contextual approach. If we do away with activating drives, needs, and motives we can ask new questions and test new ideas about the internal state of organisms as they act out their internalized understanding of their world. The task of science, in this view, is to map out the mental models organisms use in orienting themselves and acting out their goals.

\section{Illustrating the technique}

Formal research involves a conceptual framework and then uses (1) rigorous methodologies, (2) the application of standardized measurement conventions, and (3) the creation of robust models and theories within the conceptual frame or disciplinary standards. Research that does not meet these standards is rejected, but where the findings, theories, and models meet disciplinary standards they may be published to encourage critical review and replication.

Consider the following thought experiment. Imagine two points in space, A and B, and yourself as an external observer $\mathrm{O}$ as in Diagram 1.

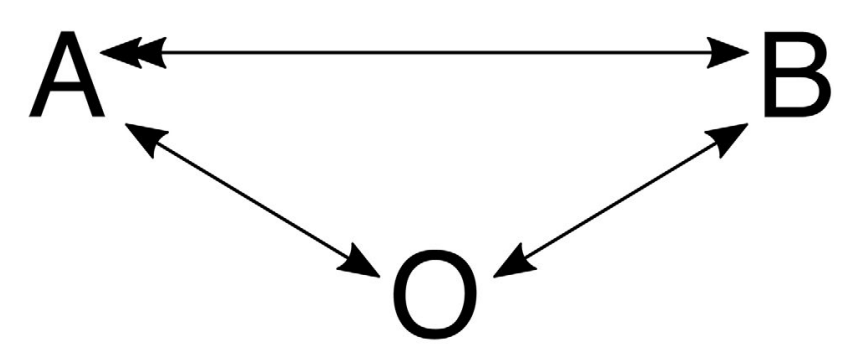

Diagram 1: Observation external to relationship.

Source: Author's depiction.

Observing both A and B from this vantage point, you can say that the relationship between $A$ and $B$ is the distance between them. You can measure this relationship objectively in terms of some standard unit (from millimeters to lightyears as appropriate). 
Now imagine yourself as being in between A and B as in Diagram 2. Now you are part of the relationship and unable to observe it from the outside, as it were.

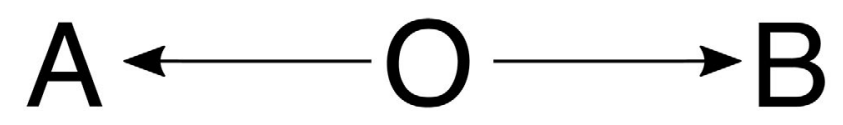

Diagram 2: Observation internal to relationship.

Source: Author's depiction.

You can walk to A then turn around and walk to B counting steps, breaths, heartbeats along the way, or use some other strategy relative to yourself. Thus you cannot experience the relationship objectively, but only subjectively in relation to how long it takes you to go from A to B. In this situation the relationship between A and B is exactly the same: they both have the same reference, but are experienced differently. The first is experienced objectively (as distance) and the other subjectively (as time). All human languages mark for tense, providing strong evidence of the universality of time. People often also think of distance subjectively in terms of the time it takes to go from A to B in objective units (hours, days, etc.), and science has combined the two, as in miles per hour, light-years, and of course in their integration as spacetime. In physics both space-time and electromagnetic fields are contexts.

Time is not the only aspect of the experience of being alive that can be objectified: so too can Gibson's affordances and all qualitative experiences. More generally, the scientific method has adopted specific measurement conventions for turning subjective experiential properties into objective measurable variables. Such properties as dimensions, duration, mass, capacity, and force are well known. People are so familiar with them that they assume measurement is a simple process. But as the philosopher J. R. Lucas (1984) makes clear, measurement is theory-loaded and far from simple. Measurement conventions include the assignment of a rational number to a distance (length), angle, or mass, but sometimes integers are used, for example in assigning atomic numbers to the chemical elements or in Möhr's scale of hardness. Sometimes a polarity (+ or -) or ( $\mathrm{N}$ or $\mathrm{S}$ ) is assigned. Sometimes a logarithmic scale is used, for example in measuring hydrogen ions in soil (soil acidity), while fields can be described not in terms of scalar numbers, but vectors and tensors. Angles can be defined in terms of radians and so on. Potentially all subjective properties can be objectified using some standardized technique.

Measurement, then, is the process of turning a subjective property into an objective one. In more formal terms, a measurement is an interactive event that maps a subjective property onto an abstract category, thereby objectifying it. The objective categories are benchmarks or anchor points for rendering a subjective property objective and permitting precise comparisons. 
The conventions associated with measurement and benchmarking are central to all scientific endeavor and go further than the simple allocation of numbers. Categorization is a process of grouping things on the basis of shared features. For example, most scientific disciplines have developed complex taxonomic systems to classify the things and processes they are interested in-the Linnaean classificatory system for naming plants and animals, for example, or the periodic table of elements, or the linguistic conventions for classifying human language families. These are contextual structures (conceptual artifacts) for turning subjective properties or features into objective entities. Instead of being a thing with feathers and webbed toes that goes quack (called duck in English), an animal with those features and behavioral traits becomes standardized as Anas platyrhynchos domesticus. Classification in itself does not enhance understanding, but it provides an agreed contextual frame within which comparisons can be rigorously evaluated, and on the basis of which new understandings can emerge.

\section{Human ecology}

Many ecologists have chosen to focus on natural phenomena as external observers. Others, particularly human ecologists, have chosen to include the human species. They see humans not just as another (albeit special) organism, but as a creative change agent that has created a scientific understanding of the world and the built environment in which most humans live. In addition, human ecologists are interested in both the objective external view of contexts (biomes, niches, bioregions, and so forth) and the subjective experience of being inside a context. It is in the inside (subjective) domain that intuitive, fast thinking, decisions are made. Contrast this with collective and deliberative decision-making where the context is objectified, scenarios proposed, options weighed up, and conclusions drawn: interactive events create new ideas and new courses of action. A decision is an event; and crucially, slow thinking is not a process, but a complex sequence of neurological events. Thinking is not a process because each component of the neurological event is dependent on a wide range of interacting factors. The number of neurons involved, the length of time since each neuron has fired, the presence of suitable neural transmitters, and so on. The pattern of firing, like the interacting patterns organisms which forms the web of life, is a dynamic event, not a simple or even a complex of processes. 


\section{Wider applications}

It is common to all living organisms (including humans) that they constantly interact with their world and change as they develop, adapt, and learn. At some point in evolutionary history some organisms evolved a capacity to change location (from one physical context to another). In short, they evolved a capacity to move. Motility enabled these organisms to choose between moving up, down, left, or right as well as not moving at all. Changing position gave motile organisms options that were not available for sessile organisms. It also provided selective pressures for evolving better perceptual strategies to find food, and better camouflage and defensive strategies to avoid being eaten. Later a new capacity emerged enabling some motile organisms to predict the movement of their prey. For a predator to secure a meal, it must aim at where it predicts its fast-moving prey will be at some future time, before it strikes. To counter this predatory advantage, prey organisms evolved a whole raft of strategies including ducking and weaving, or playing dead, and most importantly, many evolved cooperative arrangements of various sorts. Many eyes and ears are better than one, and by acting together prey animals evolved defensive strategies giving new survival options that necessitated cooperation. Finally, some organisms evolved a capacity to not only anticipate but to separate their evolved anticipatory capacity from the immediate present. They can imagine alternatives and plan.

At what point in our evolutionary history the human capacity to imagine and plan emerged is controversial. It seems likely that other primates do not have this capability, although they have some of the basic moral precepts such as a sense of fairness, empathy, reciprocity, and theory of mind, as Frans de Waal (2007) and other primatologists have demonstrated. These moral precepts can be thought of as internalized rules of the general form in context "A do B." But there can be no doubt that the capacity to imagine and share our imagined realities through language did evolve progressively along with our bipedalism and bigger brains. What distinguishes humans today from our non-human ancestors is that humans are born into an increasingly human-made world, and are in danger of forgetting that we are just another organism in the constantly evolving web of life.

The three qualitatively different evolutionary steps (to move, anticipate, and imagine) assume organisms are essentially active agents interacting with a world that each conceives differently. It is vacuous, as we have seen above, to explain patterns of behavior in terms of some underlying motive, need, or drive. The experience of pain, hunger, and all of Maslow's famous hierarchy of needs are real enough, but they have no explanatory power. It is like saying behavior $\mathrm{X}$ is the result of a drive (need, motive, or other pre-disposition) to do X, or Kipling's famous, fantastic, just so stories, which need to be told in a certain way to account for such a natural phenomenon as "How a Leopard Got its Spots." 
This is not a small point. The current work in neuroscience seeks to identify shared biochemical processes across the animal kingdom: for example, similar neurotransmitters underpinning similar functions. The existence of shared biochemical processes across species provides powerful evidence of the unity of the whole of life, but it does not account for the actions and choices of individual organisms. Hence the argument in this paper that they can best be analyzed in terms of the internalized contexts and situational factors that demonstrate what is going on.

So too with the important work on the surviving fossils and artifacts our ancestors have left behind. We are totally dependent on context, not only to date such fossils and artifacts, but to establish their function. Human ecologists can contribute to this understanding by examining the environmental contexts in which our ancestors found themselves and mapping these. For example, by mapping the use of fire in ancient times, and interpreting what managing fire and cooking enabled: to change contexts and allow humans to build a better world for themselves.

It has often been said that humans have adapted themselves to every environment on Earth, but this is far from true. What humans have done is to invent technologies that change their environment to suit themselves. In the words of Jonathan Kingdon (1993, p. 3) the emergence of technology:

had many biological consequences for the path of human evolution: the human form, human diversity, language and our relationship with nature have all been shaped by technology. Humans have become intrinsically different from apes by becoming, in a very limited but real sense, artefacts of their own artefacts.

But we are not self-made organisms. The archetypal scientific frames suggesting that we are essentially mechanistic, or part of some fully determined system, or a product of our own artifacts might suggest this, but such ideas are thoroughly mistaken. Living organisms are active agents interacting with the world, and through their interacting events create change in the world. Maybe Dawkins is right when he argues that evolution is blind (non-teleological) and directionless overall, but this is not the case for the choices of individual organisms. The cumulative effect of the little choices is huge. Grasslands, forests, and coral reefs are huge structures made and maintained by living organisms acting purposively as they develop their behavioral potential. Rainforests and coral reefs may be mindless structures, but other physical structures such as termite nests, bee hives, rabbit warrens, bower bird bowers, and the dams of beavers have associated mental structures that enable bees to find their way back to their hives, bower birds to place each ornament in a precise position, and rabbits to find their way in and around their warrens. It is the mental structures or internalized contexts that need to be studied, and this is the role of human ecology. 


\section{Conclusion}

Semantic analysis offers a tool for getting into the mindset of organisms by analyzing the meaning underpinning their behavior (in terms of affordances), and dealing with such experiences as mind and especially consciousness. For mechanistic thinkers, the nature of consciousness poses almost insuperable difficulties. Some have called it the hardest problem that science has to deal with (for a useful overview, see Blackmore, 2003). But consciousness is not something, nor is it a process. Rather, it is a subjective experience of the interactive events that result from living our lives. All living organisms experience some degree of "consciousness," as evidenced by plants when they become dormant and by motile organisms when they are anesthetized. Thinking of plants and microbes as having some level of selfawareness (or consciousness) may be a step too far, but plants vary in their activation levels (as do all organisms) and self-organize depending on external and internal circumstances. For example, plants stop photosynthesizing at night, and motile organisms become less active while asleep. Activation levels include all the internal biochemical and neural activities as well as any external observable behavior. Two chess grand masters may sit opposite each other for hours and all they do is move a small piece of wood a few centimeters every few minutes, but no one doubts their internal level of activation as they interact with those pieces of wood.

What is certain is that motile organisms, in interacting with their environments, demonstrate some sort of behavioral characteristics that enable observers to infer their subjective inner state. Context analysis gives us a new approach for mapping these inner states and dealing with such vexed questions as sentience and consciousness.

With its focus on interacting organisms, ecology needs a framework that explains the nature of an interaction explicitly. In this paper it is suggested the term event, defined abstractly as the point of interaction between two or more processes, is at the core of all ecological thinking. Events do not occur in isolation but are catalyzed by context. In other words, like a catalyst in a chemical reaction, features of a context speed up the interaction. Catalyzed events create new entities and processes, which in turn further change contexts. Darwinian evolution explains not only the emergence of new species but also explains the emergence of new contexts or opportunities/ pressures for further evolution.

Science has traditionally used three archetypal contextual frames referred to in this paper as the mechanistic, systemic, and interactive frame. The interactive frame has a much wider applicability than just evolutionary theory and can be applied at all biological levels and processes from gene expression, through growth and development, to maturation, reproduction, and death. 


\section{References}

Andrewartha, H. G., \& Birch, L. C. (1984). The ecological web. Chicago, IL: University of Chicago Press.

Blackmore, S. (2003). Consciousness: An introduction. Abingdon, UK: Hodder \& Stoughton.

Casey, E. S. (1997). The fate of place: A philosophical history. Berkeley, CA: University of California Press.

Darwin, C. (1859). The origin of species by means of natural selection or the preservation of favoured races in the struggle for life. Harmondsworth, UK: Penguin. doi.org/10.5962/ bhl.title.68064.

Dawkins, R. (1991). The blind watchmaker. Reprint edition with Appendix. UK: Penguin.

de Beer, G. (1968). Charles Darwin: Evolution by natural selection. Sydney, Australia: Thomas Nelson.

de Waal, F. B. M. (2007). Chimpanzee politics: Power and sex among the apes. Baltimore, MD: Johns Hopkins University Press.

Dixon, R. M. W. (1982). Where have all the adjectives gone? Berlin, Germany: Mouton.

Fisher, F., \& Hoverman, S. (1989). Environmental science: Strivings toward a science of context. The International Journal of Environmental Education and Information, 8(1), $11-30$.

Gibson, J. J. (1986). The ecological approach to visual perception. Missouri: Psychology Press.

Goddard, C. (2011). Semantic analysis: A practical introduction. 2nd Edition. Oxford, UK: Oxford University Press.

Goffman, E. (1959). The presentation of self in everyday life. University of Edinburgh Social Sciences Research Centre: Anchor Books.

Harari, Y. N. (2015). Homo Deus: A brief history of tomorrow. London, UK: Vintage.

Kahneman, D. (2011). Thinking fast and slow. United Kingdom: Penguin.

Kingdon, J. (1993). Self-made man: Human evolution from Eden to extinction. New York, NY: John Wiley \& Sons Inc.

Lakoff, G., \& Johnson, M. (1980). Metaphors we live by. Chicago, IL: University of Chicago Press.

Lakoff, G., \& Johnson, M. (1999). Philosophy in the flesh: The embodied mind and its challenge to western thought. New York, NY: Basic Books. 
Leibniz, G. W. (1903). Alphabetum cogitationonum humanarum. In L. Couturat (Ed.), Opuscules et fragments inedits de Leibniz. Paris: Presses Universitaires de France. (Reprinted 1961. Hildesheim: George Olms.)

Lucas, J. R. (1984). Space, time and causality. Oxford, UK: Clarendon Press.

Midgley, M. (2003). Myths we live by. London, UK: Routledge.

Peterson, J. B. (1999). Maps of meaning: The architecture of belief. London, UK: Routledge.

Prigogine, I., \& Stengers, I. (1984). Order out of chaos: Man's new dialogue nature. London, UK: Fontana (Bantam).

Reddy, V. (2010). How infants know minds. Boston, MA: Harvard University Press.

Riskin, J. (2016). The restless clock: A history of the centuries long argument over what makes living things tick. Chicago, IL: University of Chicago Press. doi.org/10.7208/ chicago/9780226303086.001.0001.

von Uexküll, J. J. (1957). A stroll through the worlds of animals and men: A picture book of invisible worlds. In C. H. Schiller (Ed. and trans.), Instinctive behaviour: The development of a modern concept (pp. 5-80). New York: International Universities Press, Inc. doi.org/ 10.1515/semi.1992.89.4.319.

Wierzbicka, A. (1985). Lexicography and conceptual analysis. Ann Arbour, MI: Karoma Publishers.

Wierzbicka, A. (1988). The semantics of grammar. Amsterdam, Netherlands: John Benjamins.

Wierzbicka, A. (1996). Semantics: Primes and universals. Oxford, UK: Oxford University Press.

Wierzbicka, A. (2003). Cross-cultural pragmatics: The semantics of human interaction. Berlin, Germany: Mouton de Gruyter.

Wierzbicka, A. (2014). Imprisoned in English: The hazards of English as a default language. Oxford, UK: Oxford University Press. 
This text is taken from Human Ecology Review, Volume 25, Number 1, 2019, published by ANU Press, The Australian National University, Canberra, Australia. doi.org/10.22459/HER.25.01.2019.07 